\title{
Process of change: states, transitions, and determinants
}

\section{Alessandro FENICIO}

Univ. Grenoble Alpes, CNRS, Grenoble INP, LIG, F-38000, Grenoble, France

Alessandro.Fenicio@univgrenoble-alpes.fr

\section{Yann LAURILLAU}

Univ. Grenoble Alpes, CNRS, Grenoble INP, LIG, F-38000, Grenoble, France

Yann.Laurillau@imag.fr

\section{Gaëlle CALVARY}

Univ. Grenoble Alpes, CNRS, Grenoble INP, LIG, F-38000, Grenoble, France

Gaelle.Calvary@imag.fr
Abstract. The goal of persuasion is to change the behaviour or the attitude of a person without using any form of coercion (Oinas et al. 2010). In the last ten years, several models, approaches and theories have been developed in the research field of persuasion, producing a copious scientific literature. Different reviews of the state-of-the-art focusing on specific aspects have been proposed. Pindel et al. (Pinder et al. 2018) for example analyse the state of the art under the perspective of the mechanisms that lead to the habit forming. In this work, we report a state-of-the-art review on the key elements of the process of change using the concepts of states, transitions, and determinants to propose a common generic paradigm. We conclude with a discussion about the operationalization of persuasive processes and with a comparative analysis on the reviewed theories.

Keywords: process of change, persuasion, persuasive technologies.

Résumé. Si le but et les garde-fous éthiques de la persuasion sont aujourd'hui bien compris, la littérature est abondante et les analyses critiques multiples, sans qu'un langage de comparaison n'ait été défini. Cet article propose les concepts d'états, de transitions et de déterminants pour caractériser les travaux de la littérature et ainsi en faciliter la compréhension et la comparaison. L'opérationnalisation de ce cadre ouvre des perspectives intéressantes au domaine.

Mots-clés : processus de changement, persuasion, technologies persuasives. 


\section{Introduction: defining A PROCESS Of CHANGE}

Persuasive technologies were initially introduced by B.J. Fogg with the term "Captology" (computers as persuasive technologies) (Fogg 1998). They were intended to alter one or more particular behaviours of users. In the last ten years, their principles have been applied to mobile, web and wearable technologies, permitting the growth of a dedicated research field.

Human Computer Interaction has investigated how to operationalize the persuasive theories, which are grounded in social psychology and cognitive sciences. Nowadays, the applications of persuasive systems are numerous and the research field has produced a copious literature made of formalizations, models and frameworks, not always compatible with each other.

The Persuasive Technologies subject presents several challenges, such as the maintenance of the behaviour change over the time or the issues coming from ethic and privacy (Pinder et al. 2018). Also figures the need of bridging the gap between the theoretical models available in the literature and the concrete implementations in practice. Nowadays developers of interactive systems often approach persuasion as a pick-and-mix cocktail of strategies and models, which may result difficult to be reliable, especially from an evaluation point of view.

Pinder (Pinder et al. 2018) reviewed the literature in persuasion, focusing on habit formation. The outcome is the theorization of a new model called the HAM (Habit Alteration Model) able to synthesize most of the classical theories in persuasion. However a persuasive interactive system, in addition to the theoretical foundations, also needs concrete interactive features to support and sustain the user in the process of change. For this reason, in this work, we investigate the key elements of the process of change in order to give new clues to operationalize the development of interactive persuasive systems.

\section{RESEARCH PROBLEM:}

$\checkmark$ The state of the art in persuasion is copious which makes it difficult for non-experts to master all the different approaches.

$\checkmark$ This ample literature is often reflected by a pick-and-mix cocktail of concepts/features when developers approach the design and the implementation task.

In order to accomplish our research purpose, we review the state-of-the-art in persuasion focusing on the characteristics of the process of change. Successively we enlighten some key elements necessary to operationalize persuasive interactive systems and finally we perform a comparative analysis. 


\section{CONTRIBUTION OF THIS RESEARCH:}

$\checkmark$ Review of the state of the art in persuasion evidencing the concepts of states, transitions, and determinants for each approach.

$\checkmark$ Review of the key elements for implementing persuasion.

$\checkmark$ Comparative analysis of the reviewed persuasive approaches as resources to support the operationalization and implementation of persuasion.

\section{Persuasion And the process of changen state-OF-the-ART}

The English Oxford Dictionary gives the following definition for the word "process" "A series of actions or steps in order to achieve a particular end", while the word "change" is defined as "An act or process through which something becomes different". Both indicate an initial and final status as well as the concept of transition. Indeed the ultimate goal of persuasion consists of changing a given behavior.

Systems in charge of carrying on this change are called "behaviour change support systems" by Oinas Kukkonen, defined as "an information system designed to form, alter or reinforce attitudes, behaviours or an act of complying without using deception, coercion or inducements (Oinass et al. 2010). B. Fogg defines the persuasive technologies that address behaviour change as "any interactive product designed to change attitudes or behaviours by making desired outcomes easier to achieve" (Fogg 2009).

A behavioural change process is not instantaneous. Instead it is a set of transitions that drives individuals from an initial state through a series of events altering their habits, in order to achieve a final state where the desired change has been (durably) achieved. Pinder et al. (Pinder et al. 2018) analyse different elements of the process of change combining them into the HAM (Habit Alteration Model) model. In our work, we proceed using a similar approach in reviewing the state-of-the-art, but aiming to investigate a new direction to operationalize the process of change.

Operationalizing the process of change means to have a generic implementable structure able to describe and embed its elements. We propose to adopt a simple representation of process: an automaton made of states, transitions, and determinants. The states represent the several steps that the user has to go while changing (ex. contemplating the change, preparing to change, maintaining the habit). A transition is a link between two states. For example, after having performed a first behaviour, a transition may guide the user to perform a successive one, possibly more complex than the previous one. The fact that the user has mastered the first behaviour may be a determinant factor enacting the transition. Thereby the user successively progresses along the states, towards the change.

In the following sections we review different approaches of the state-of-the-art with the objective of finding a transcription, for each model or approach, by using an automaton made of states, transitions and determinants. After reviewing the main concepts for each theory, we dedicate a special paragraph called "States, transitions and determinants", whose objective is to separate the presentation of the theory from our work of representation by using an automaton. All these special paragraphs will be finally synthetized at the end of the work by using a dedicated table. Designers and developers who wish to operationalize the 
model of persuasion will thereby have a new clue to compare the theories and elicit the more adequate ones for their purposes.

\subsection{Behaviourism and influence}

Behavioural scientists and social psychologists have developed a huge literature of models and methods to help users in changing. These contributions that have gone beyond their research field, and have ultimately been applied also to products design, advertisement and marketing. Scientists of these fields study the contextual factors that bring an individual to perform a given action. Assuming a procedural approach to the change, these elements represent the determinants that trigger people to pass from a stage to another in the process. In the following paragraphs, we focus on these specific determinants, linked to behavioural science and social psychology.

\subsubsection{Operant conditioning}

Behaviourists see habits as stimulus-response pairs formed outside conscious decision-making via two mechanisms of associative learning: classical and operant conditioning. The classical is based on creating a stimulus-response pair via repetition: the individual repeats the behaviour every time that the stimulus is driven. In operant conditioning theory initially investigated by Skinner (West and Brown 2013), a "Three-term contingency (SD-R-Rf)" is used: a discriminative stimulus (SD) (the context) sets the occasion for a specific behaviour/response $(R)$ to be reinforced (Rf). The reinforcement could aim either at increasing or decreasing the frequency of the response for a given context. These reinforcements are found to be effective and are actually used not only in the design of persuasive technologies but also in other types of context in which the user is involved in a repetitive process such as marketing, learning, and gambling (e.g. slot machine games).

Operant conditioning focuses also on the study of the efficacy of different types of rewards, such as using a fixed or variable ratio or a fixed or variable interval (Staddon et al. 2003)(Bijou 1957). Relatively to the reward subject, Nir Eyal theorized a model for habit forming associated to technology (Eyal 2014) where three types of rewards are defined: the "reward of the hunt" (materialized in resources and goods such as money and food), "reward of the self" (represented by personal gratification for being consistent with one's own ideas, mastering an ability, or for completing a particular task) and "reward of the tribe" (expressed by another user through social-likes, comments, ratings, and reviews).

\section{States, transitions, and determinants}

The theories of operant conditioning do not make an explicit reference to a set of states to be travelled by user during the process of change. However the mechanism of ThreeTerm contingency describes a temporality from the moment in which the behaviour is not present, to the moment in which it is performed and reinforced. For this reason, we propose to picture the approach using three states, antecedent (before the behaviour), the behaviour and its consequence (after the behaviour). The environmental conditions or a stimulus determine the performing of the behaviour by the individual. The reinforcement or the punishment can be used as determinant to construct the consequence: reiterating the behaviour for instance or suppressing it. 


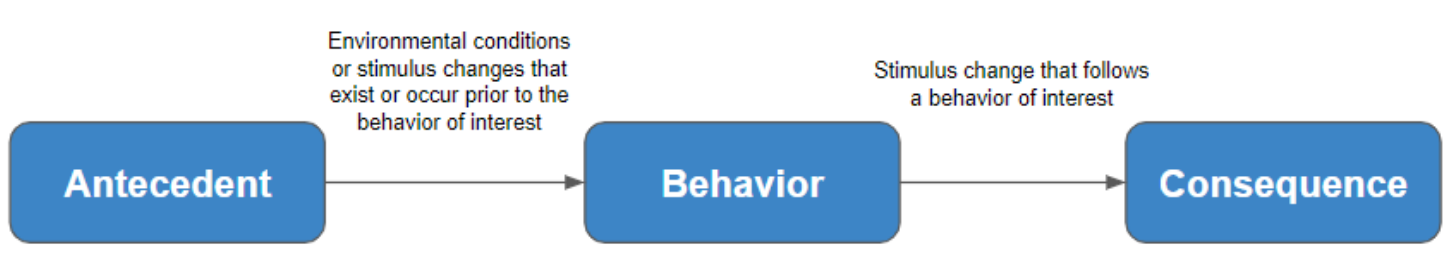

\subsubsection{Influence}

Reinforcements may take the form of social reconnaissance such as for example being rewarded by someone else in private or public forms (for example by a public message on social network). Robert Cialdini, one reference in the field of influence, has identified a set of influencing people's behaviour principles (Cialdini 1987): "reciprocity" (tendency to return a favour), "commitment and consistency" (by committing to an idea or a goal orally or in writing, people are more likely to honour that commitment), "social proof" (people will do things other people succeeded in), "liking" (people are more easily persuaded by people they like) and "authority" (people tend to obey to authority figures, even if they are asked to perform objectionable acts). Authority has been explored by Milgram who measured the willingness of subjects to obey to an authority figure who was instructing them to perform acts conflicting with their personal conscience (Milgram et al. 1974).

\section{States, transitions, and determinants}

The theory of influence does not mention any form of state or transition. However, the principle of influence can be seen as determinants for other state-transition approaches. In this case, we can represent the determinants as activators of transitions between two generic states: the one in which the behaviour is not happening, and a second one in which the behaviour is happening thanks to the use of one of the principle of influence as determinant of the transition.

Figure 2. Proposed automaton

\begin{tabular}{|c|c|c|} 
Behavior not \\
performed \\
\hline principles of influence
\end{tabular}

\subsection{From dual Process Theory to the likelihood model}

The dual process theory has been initially formulated by William James (William 2013) and then re-elaborated in different studies in the social and psychological fields. The theory describes two different kinds of thinking: a first one based on an associative approach, which is fast and unconscious; a second one based on true reasoning, which is slow and rational. In particular, William James claimed that the experiences of people and their past actions influence the way they approach choices, bringing them to natural repetitive behaviours. On the contrary, new contexts, situations, or unexperienced problems bring people to true reasoning creating new associative knowledge.

Based on the dual process theory, Cacioppo (Petty et al. 1986) has elaborated the likelihood model that explains how a persuasive message is elaborated by people and brings 
to an attitude change. Once the message has been delivered to the individual, it may lead to two types of persuasion. A first one which likely resulted from a person's careful and thoughtful consideration of the true merits of the information (central route), a second one, more likely to occur, is the result of cues in the persuasion context that induce the change without necessitating scrutiny of the true merits of the information presented (peripheral route) (Petty et al. 1986).

If the individual is motivated and able to process the message, the central route is travelled. In this scenario, the individual processes the information, elaborating favorable or unfavorable thoughts about changing the attitude. If these thoughts (either favorable or unfavorable) are predominant, they will bring to a cognitive structure change, otherwise they will be redirected to a peripheral route as a cue. When the individual is not able or motivated to elaborate the persuasive message, the peripheral route will be also travelled building to create new peripheral cues. These cues may eventually concur to the evaluation of new persuasive messages to progress in the central route.

Figure 3. Central and peripheral routes to persuasion (Petty et al. 1986)

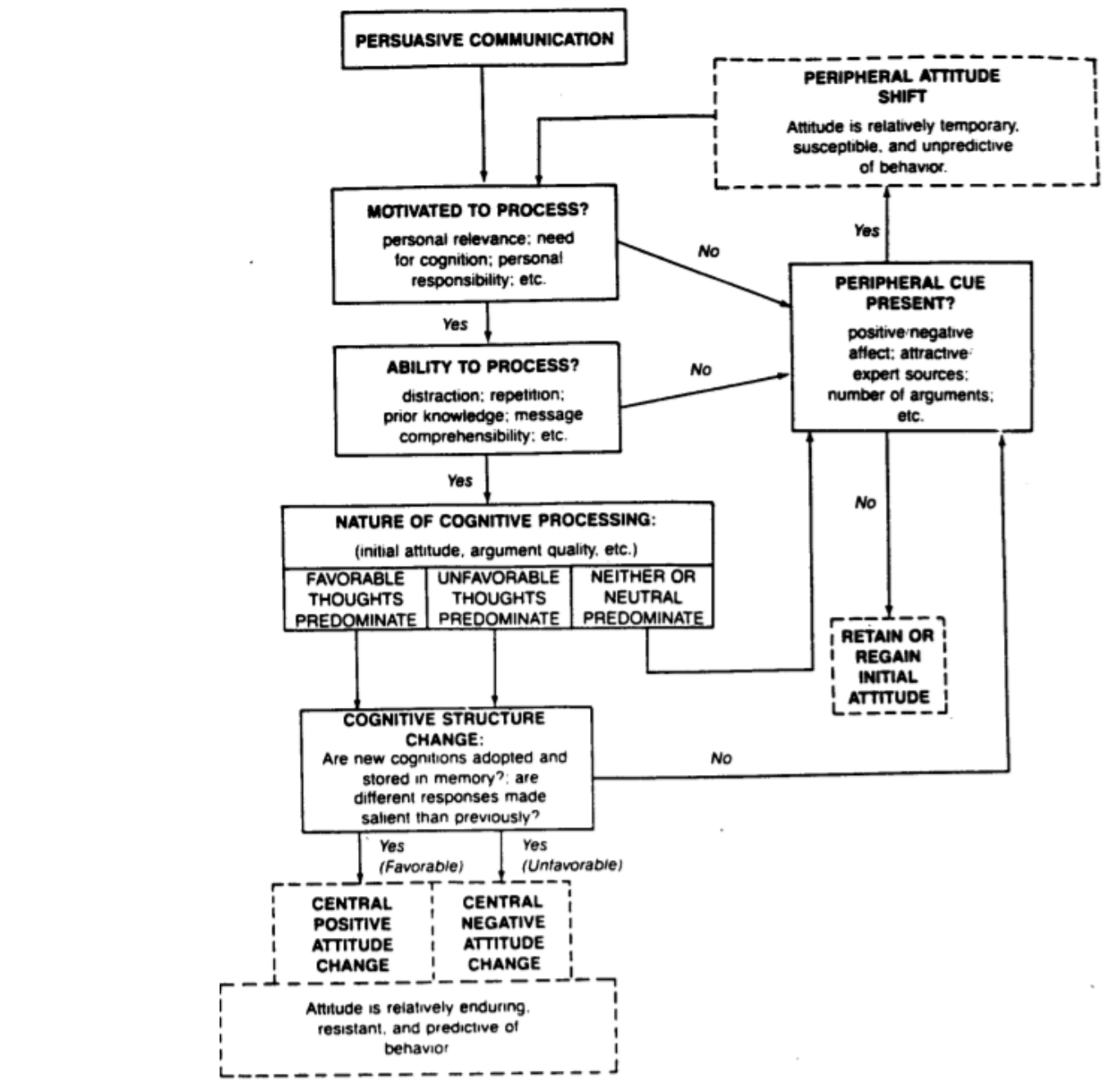

States, transitions, and determinants

The initial stage is the moment in which the persuasive message is delivered. A set of transitions guides the process through the central or peripheral route where an evaluation stage is responsible to estimate two determinants: the ability and the motivation. In a first scenario, the response of this evaluation may be that motivation and ability are not high 
enough, which brings to travel the peripheral route that we may represent by using two states: the first where a peripheral attitude change happens (and the central route will be travelled again) or the second where the attitude remains unchanged (final state). In the opposite scenario (when the motivation and the ability are high enough), a transition in the central route brings to a state where a positive (or negative) shift creates an impression in the receiver. This impression will finally bring to the final state where the attitude change in the central route of the receiver will happen (final state).

Figure 4. Proposed automaton

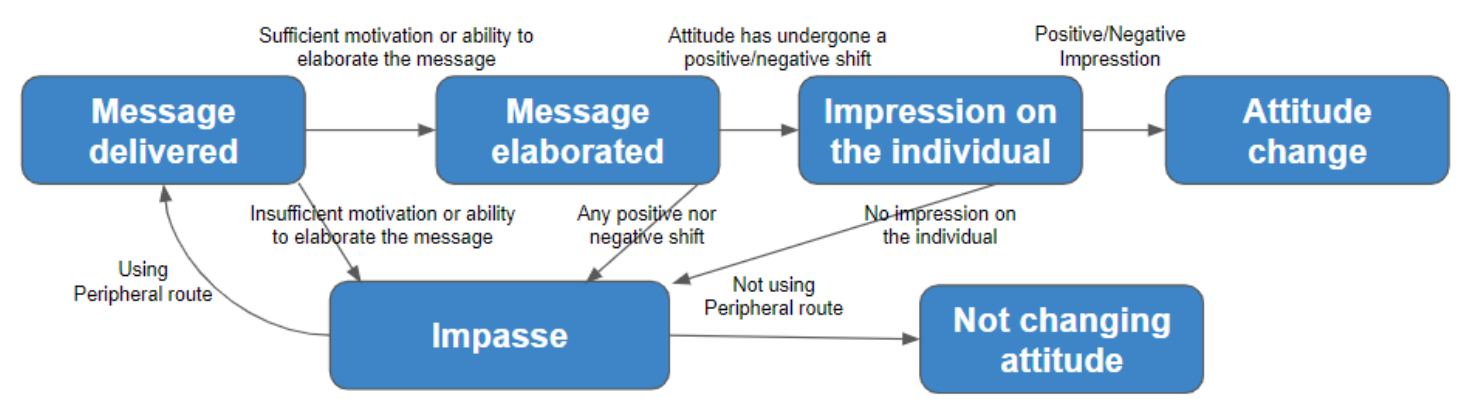

\subsection{Context and social cognitive theory}

In the theories mentioned so far in this work, we have elicited the context as fundamental factor to operate the transitions among the states of a behavioural change. Context is key in persuasion and deserves to be carefully analysed in order to take advantage of its valuable information.

A. K. Dey defines context as "any information that can be used to characterize the situation of an entity. An entity is a person, place, or object that is considered relevant to the interaction between a user and an application, including the user and applications themselves" (Dey 2001). This definition has been often used to describe the huge amount of information that context involves. Behaviour is strictly influenced by context and for this reason, it is necessary to explicit this aspect when speaking about its causality. This topic has been approached by several scientists such as Skinner and Bandura who mentions that "the behaviour, the environment, the user and the activity form a reciprocal causality. Each of these three elements influences the other two with an intensity that varies according to the situation and the current activity" (Bandura 2001).

Bandura goes further asserting that the determinants of behaviour are originated by a triad of factors: the "cognitive factors" (ex. knowledge, expectation, attitudes), the "environmental factors" (ex. social norms, access in community, influence on others) and the "behavioural factors" (ex. skills, practice, and self-efficacy). 


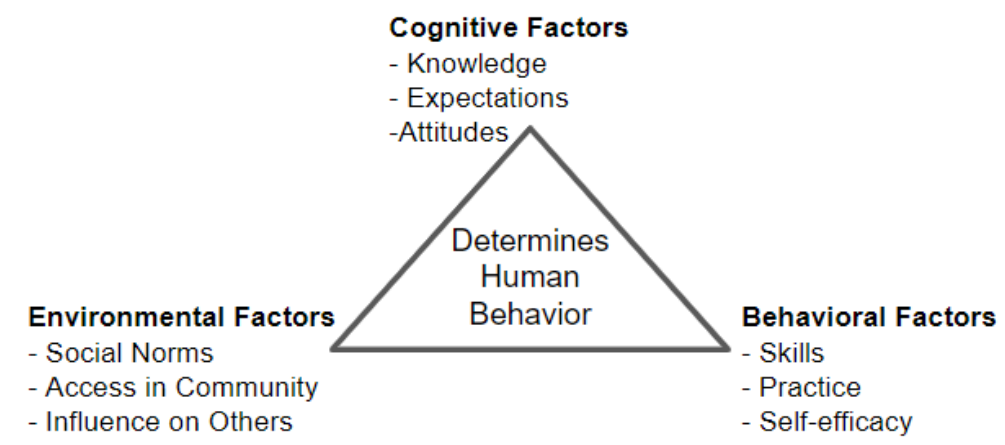

An example of the impact the context has on individuals is CRegrette (Fenicio et al. 2015) where a persuasive device was designed for smoking cessation producing effective or non-effective results depending on the user's context. In particular, the system provided notifications to the users to avoid/reduce smoking at different moments of the day. The system was found to be effective when the notifications were sent in the morning, before going to the workplace. This way, users were taking this suggestion as a challenge for the whole day. Proposing the same suggestion during work hours was ineffective. In some cases, CRegrette was even counterproductive as the action of smoking was triggered to the subjects when at that particular instant, users were not interested in smoking (wrong context).

\section{States, transitions, and determinants}

In the perspective of the progression on a process of change made of states transitions and determinants, the contextual variables figure as activators of the transitions between states, and indeed as determinant factors. For example, the environmental factor of "influence on others" may be used to persuade sceptic users in adopting a certain behaviour that other users have already adopted (ex. some friends) triggering a state change. A combination of determinants may also trigger the transition, aligned with Bandura's theory that combines the simultaneous use of different determinants of behaviour (cognitive, environmental and behavioural factor).

Figure 6. Proposed automaton

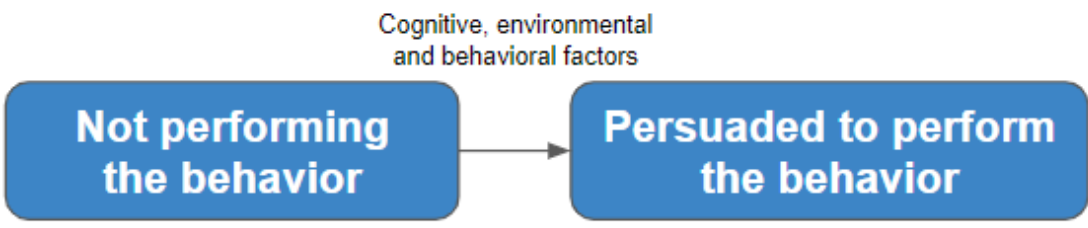

\subsection{The theory of planned behaviour}

The theory of planned behaviour formalized by Ajzen (Ajzen 1991) is an extension of his precedent theory called reasoned action. The theories attempt to predict how people will behave on the basis of their precedent attitudes and behaviours. The theory is built on three key points. The first investigates what is the attitude toward a certain behaviour: a personal belief that a certain behaviour makes a positive or negative contribution to one's own life. The point considers the "subjective norms", focusing on everything around individuals: their 
social networks, cultural norms, group believes, etc. Third point is "perceived behavioural control" (the novelty in respect to the previously formalized theory of reasoned action) which expresses the person's confidence in performing a certain behaviour. These three points influence one's intention to change. The intention however is not sufficient to change, thus Ajzen proposed that perceived behavioural control should moderate the relation between the intention to change and the actual performance of the behaviour (this is represented by the dashed path in Figure 7).

Figure 7. Theory of planned behaviour (Ajzen 1991)

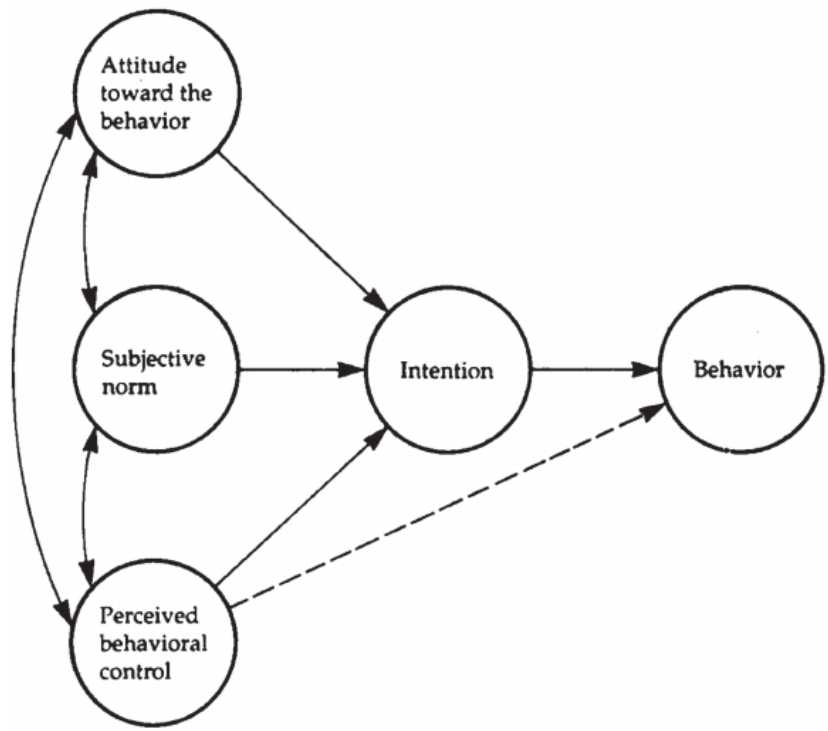

\section{States, transitions, and determinants}

We propose three main states for this theory. In the first state, the intention is being formed by an evaluation of attitudes, subjective norm and perceived behavioural control. These determinants trigger a transition to a stage in which the intention is ultimately formed. Before arriving to the intention, multiple iterations of the first stage may be necessary. The final transition toward the third is triggered by the determinant of perceived behavioural control, which moderates the intention to perform the behaviour.

Figure 8. Proposed automaton

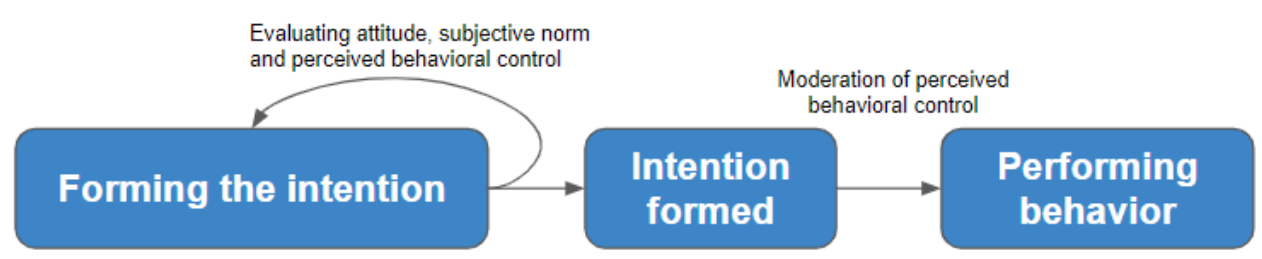

\subsection{Motivation and Ability}

In behavioural theories, motivation and ability are often considered as contextual factors describing individuals involved in a change. Thus motivation and ability are core concepts of different theories and models. In the following, we analyse some of them, describing how these two variables are represented and what is their role in the behaviour change process.

In the Fogg Behaviour Model, for example, three key elements must be present at the same time in order for users to perform a certain behaviour. These are the motivation to 
change (to perform the given behaviour), the ability to change (resources, physical condition, and knowledge) and the presence of a prompt (an element that enacts the action). Motivation and ability are represented as axes in Figure 9 while the prompt is represented by a transversal dashed line. This latter represents that a trade-off between ability and motivation must be encountered in order to perform the target behaviour. Fogg explains that the user's motivation is not constant: it may be affected by some elements central to the human experience such as Pleasure/Pain, Hope/Fear, and Social Acceptance/Rejection. Similarly, the ability may be increased using the following six factors: time, money, physical effort, brain cycles, social deviance, and non-routine.

Figure 9. The Fogg's Behaviour Model (Fogg 2009)

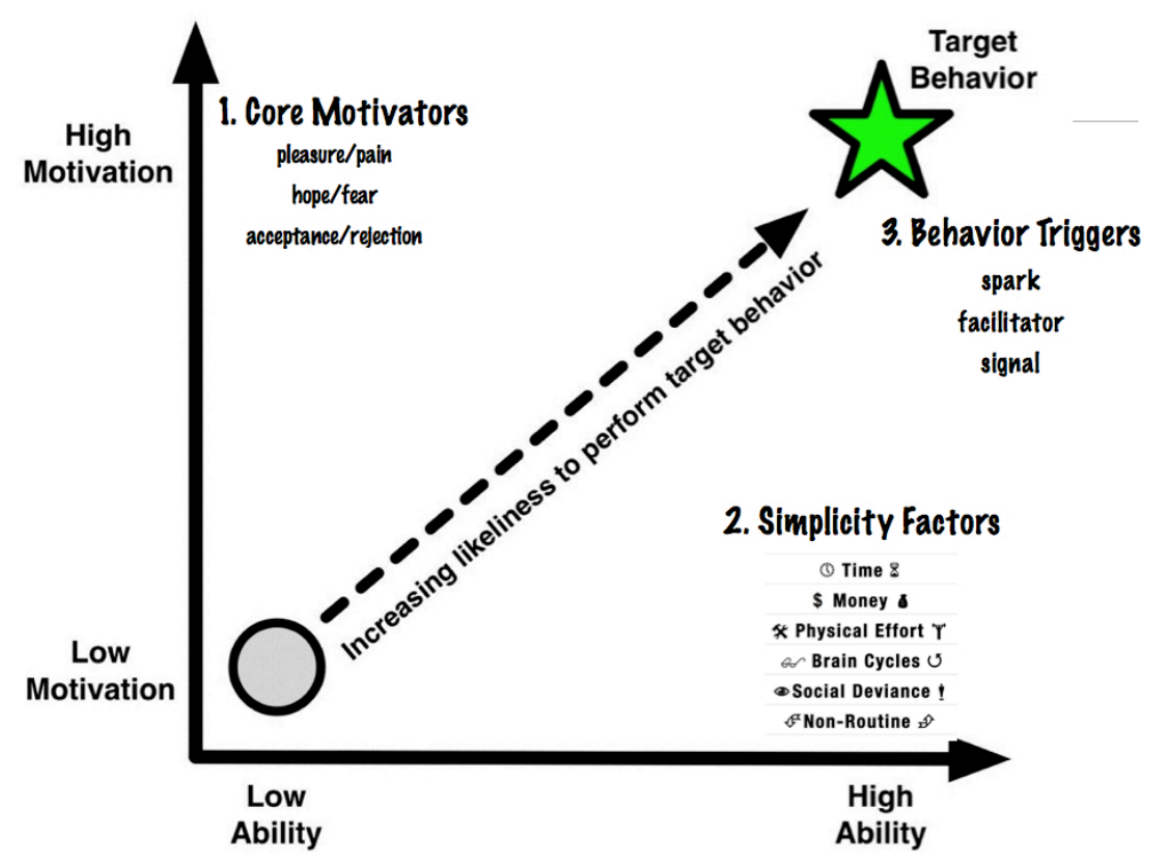

B.J. Fogg illustrates the variability of motivation and ability with the concept of "motivational waves". The theory explains that users should be triggered with small and easy behaviours (named "baby steps") in order to gain confidence in themselves increasing their level of motivation. For a person who wants to start jogging, a suggested practice would be to start with an easy and short itinerary. When motivation is high, the persuasive system should prompt users to perform more difficult tasks (in the case of jogging, try a harder itinerary) or invest this motivation to gain new abilities, for example, to find a new spot where to go jogging or to buy a new pair of shoes.

\section{States, transitions, and determinants}

We propose to represent the variability of motivation and ability using three different states: a first one, where motivation and ability are not sufficient to perform the behaviour, a second one, that can be reiterated, where an intermediate behaviour is performed to increase the levels of ability and motivation, and a third one where the two variables are high and thanks to the presence of the prompt the behaviour happens. 


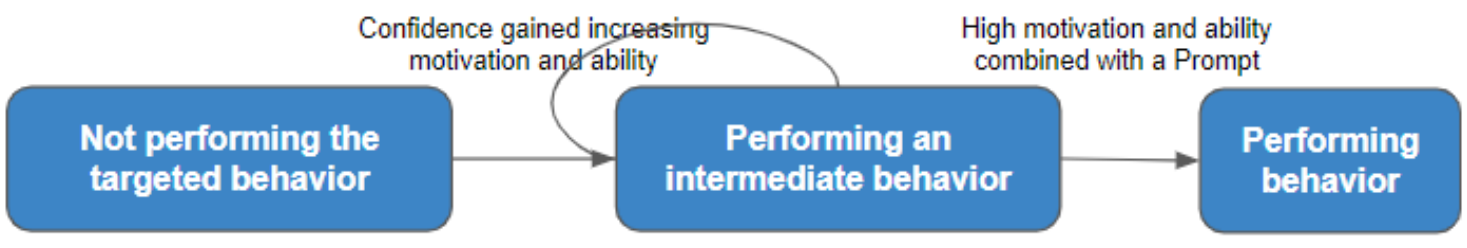

\subsection{From the Motivation-Opportunity-Ability model to the COM-B model}

The Motivation Opportunity Ability (MOA) model proposed by Ölander and Thøgersen (ThØgersenet 1995) comes from the marketing field. It has been used several times to explain behaviours (Hamari et al. 2014) and persuasive techniques (Huges 2007). Also, this model mentions the Motivation (combination of attitudes and social norms that forms an intention) and the Ability (habit and knowledge needed to perform the behaviour). The opportunities are contextual factors and products available to perform the behaviour. Maclnnis (Maclnnis et al. 1991) explains that the adoption of a behaviour by subjects is influenced by their motivation to adopt the behaviour moderated by their capacities and the opportunities offered by the environment. The COM-B model also analyses the necessary motivation and (Cap) ability in order to produce the outcome behaviour, but it also includes a framework called the Behavioural Change Wheel (Michie et al. 2011) to operationalize the persuasive strategies.

Figure 11. Motivation Opportunity Ability model (on the left), COM-B model (on the right)
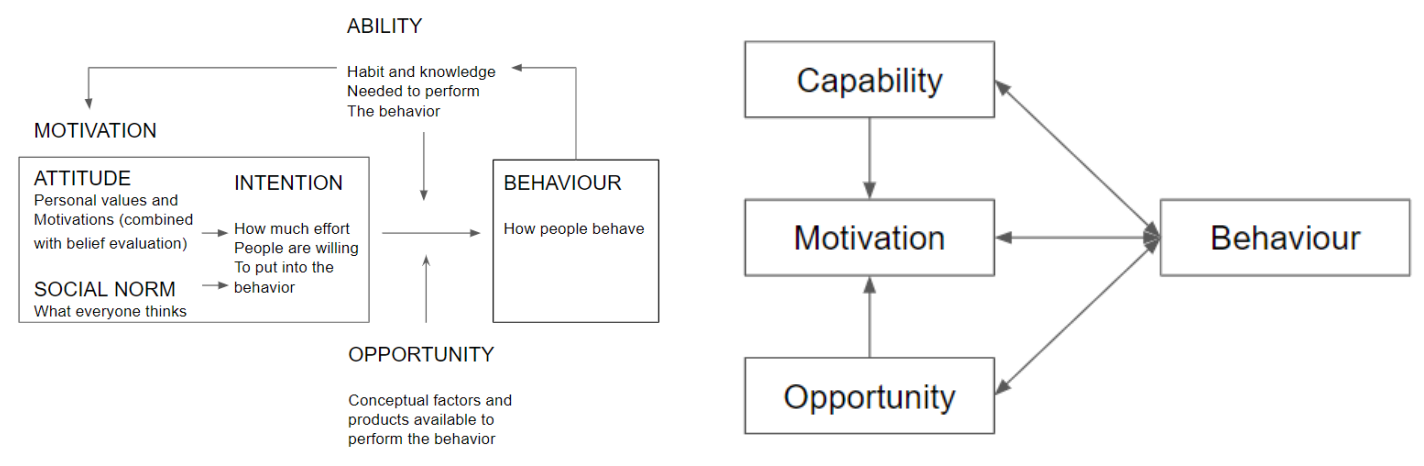

The COM-B Model and the MOA model use similar causal factors. The ability factor results from the combination of psychological and physical capabilities: the motivation is given by reflective and automatic motivation while the opportunities are provided both by the social and the physical environment. Additionally to the MOA approach, the COM-B model comprehends also a framework, the Behaviour Change Wheel, that helps to use the different persuasive strategies. This framework was produced from a literature review of 1267 scientific articles (see Figure 12). 


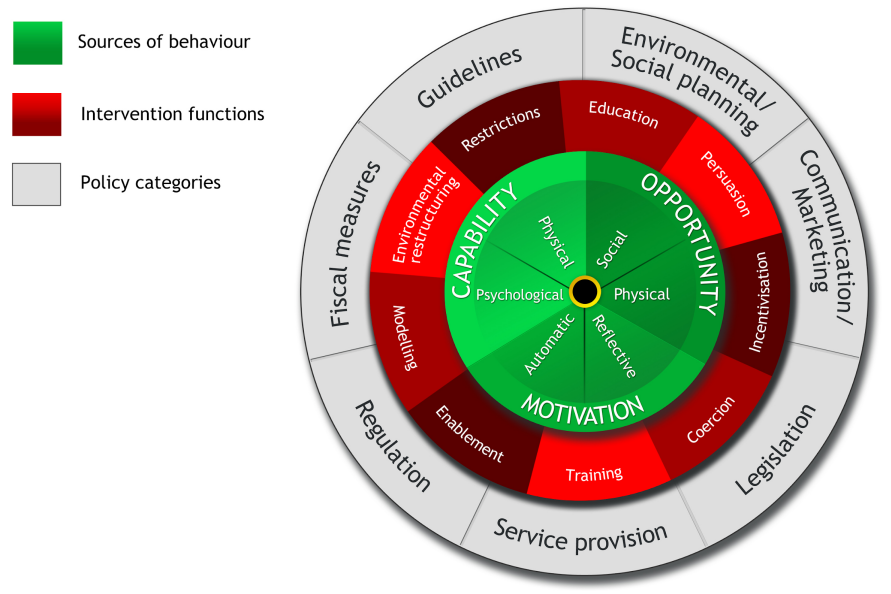

The Behaviour change wheel combines the sources of behaviour (motivations, abilities and opportunities) with a set of intervention functions (restriction, education, persuasion, incentivisation, coercion, training, environmental restructuring, modelling and enablement) and a set of policies (communication marketing, guidelines, fiscal, regulation, legislation, environmental/social planning and service position). In addition, the framework provides the "links" between these components, such as which intervention function can be used for each source of behaviour, or which policy categories work with each intervention function. These links help choosing the intervention to be actuated to enact the behaviour change.

\section{States, transitions, and determinants}

The MOA model (operationalized for example through the COM-B model) does not make explicit a set of states. We can however propose to describe the process using a first state (motivation) in which the intention is formed through determinants of social norms and attitude. From this state, a transition triggered by the determinants opportunity and ability bring the user to perform the behaviour. A last transition from this state to the initial one is triggered by the determinant "discovering new abilities" that brings the individual to a new motivation state.

Figure 13. Proposed automaton

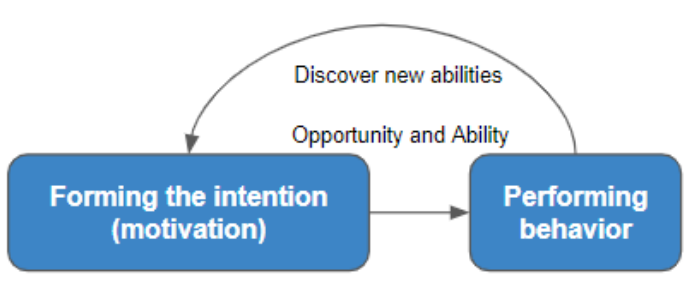

\subsection{The Transtheoretical Model of Behaviour Change}

The Transtheoretical Model of Behaviour Change (TTM) (DiClemente et al. 1998) was theorized by Prochaska and Di Clemente. It is widely used to describe the process of change. TTM is based on six stages of change, ten processes of change and the concepts of decisional balance and self-efficacy. The model describes the stages that a person must go through when dealing with a behavioural change. The first stage is "pre-contemplation," 
where people are not intending to take any action in the foreseeable future (ex. not aware of the benefits from jogging); in this stage, people may also not be aware that their behaviour has to be changed. The second stage is "contemplation" where the person is considering the pros and cons of their continued action envisaging that a change may be taken (ex. jogging is useful to reduce weight). In the "preparation" stage, people prepare the strategy to take the action in the short term (ex. going to buy shoes for jogging). The action is the stage in which the user has made specific modifications in the behaviour (ex. going to take a first jogging path). Finally, in the "maintenance" stage the person tries to keep the change active, preventing from relapsing (ex. jogging is now a weekly activity).

Figure 14. The stages of the Transtheoretical Model of Behaviour Change

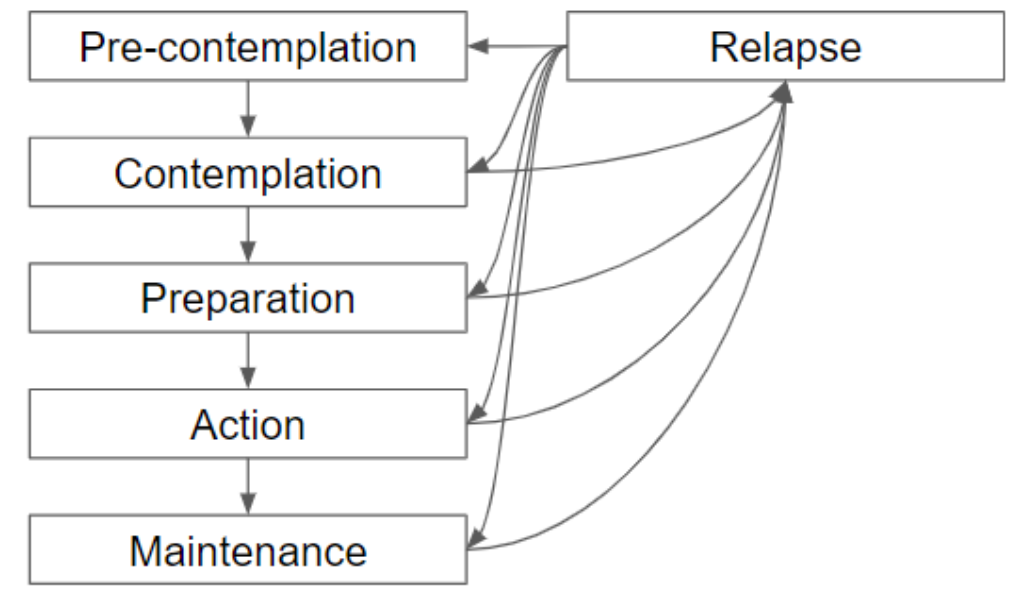

The model presents several strong points. In particular, it discretizes the change in predefined states and is applicable to several domains (notably healthcare). The discretization of the states of the model has been used as a structuring framework to guide the design of persuasive systems. An example of this approach can be found in Greenberg et al. in "One Size Does Not Fit All" (He et al. 2010) and in the article "Persuasive Events and User's Roles in Mobile-Based Interactive Solutions for Nature Discovery" (Fenicio et al. 2017). On the other hands, the model also presents few limitations such as assuming that people make rational choices rather than acting non-consciously as in habits (Pinder et al. 2018), or the difficult evaluation of the transition between the stages and of their temporality.

\section{States, transitions, and determinants}

In the Transtheoretical model of behaviour change, the concept of process of change is embedded in its definition: the five stages can be represented as five states of the model while the transitions between the states are achieved using the ten processes of changes as determinants. For example in order to pass from the state related to the action behaviours to the one related to the maintenance behaviour, it is possible to employ a reward technique (that figures among the ten processes of change of the model) as determinant factor of the transition. For readability, in the proposed automaton we give just one determinant for each transition among the ones employable according to the theory, and we do not represent the phenomenon of relapse. This latter could have been represented by drawing for each state a transition to each precedent states. Moreover the model does not clearly specify the permanence of the individual in each state, for this reason multiple iterations of each state may occur. 


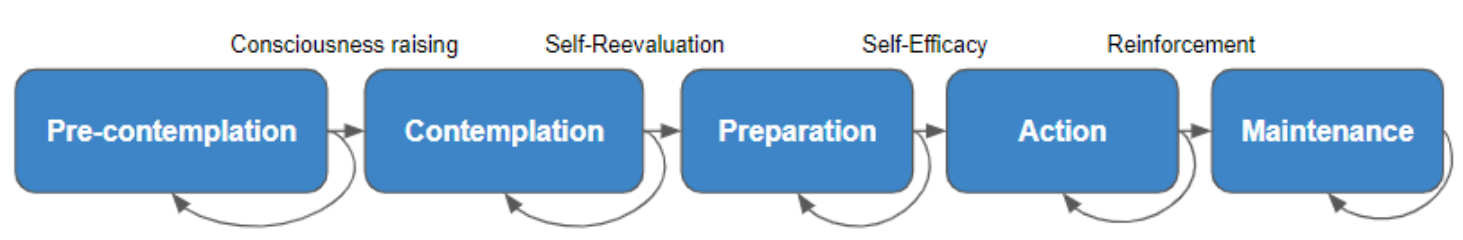

\subsection{Ambient Persuasion Model}

Kaptein has investigated the personalisation of the persuasive means with the objective to improve their effectiveness (Kaptein 2012). He also investigated ambient persuasive technologies, proposing a model that structures the knowledge from social sciences on persuasion, attitude and behaviour change (Kaptein et al. 2010). Kaptein considers two fundamental axes for persuasion: the first that describes the delivering and reception of the persuasive message to the individual, and the second that describes the actual process of changing attitudes and behaviour towards a state of maintenance. In the model, several approaches and models are discussed to characterise these two axis. We give some examples of them to describe the characteristics of Kaptein's model, readdressing the reader to a complete study of his article (Kaptein et al. 2010) for completeness.

The first axis (from source to receivers) discusses the implication of multiple sources of persuasive requests and the social environment of the receiver. Milgram's experiment (Milgram et al. 1974) is for example mentioned as an example of single source. An authority figure is perceived as more persuasive for the individual and then more effective. In the same perspective the principles of Cialdini (Cialdini 1987) can be used to improve the effectiveness of delivering the persuasive message. For example (for the liking principle), individual will pay more attention to messages delivered by people they like (ex. friends, public figures). Examples of multiple sources take into account mechanisms deriving from more individuals involved in the change. For example the number of people of reference that has engaged into the change, the social proof of people succeeding in the change and the consensus gathered by change are factors that impact persuasiveness.

The second axis (from attitude change to maintenance) discusses the gradual process of changing, as it happened in the first axis, several models are evoked. In the first part of second axis of the model, Kaptein focuses on attitudes, mentioning the notions that contribute to forming them. Mental accessibility, Mood, Ambivalent attitudes are some examples of these notions, completed with detailed analysis on the easy of evaluating and retrieving object from the individual memory. Kaptein evokes the difference between affective- and cognitive-based attitudes, explaining that the origin of the attitudes influences how they can be changed. The axis then threats how the information is processed, and how the decision on performing or not the behaviour is taken. In order to describe this part, Kaptein uses some models in the literature as for example the elaboration likelihood model or the motivation ability opportunity model, previously discussed in this work. Besides the rational central route many attitudes are formed and executed without the elaboration of the receiver. For this reason Kaptein dedicates a particular attention to the subject of the mental shortcuts, relating them to the principles of Cialdini (Cialdini 1987). The last concept of this axis concerns the behaviour maintenance. In this perspective, the aforementioned approaches of behaviourist are employed: the classical reinforcement and the operant conditioning. 


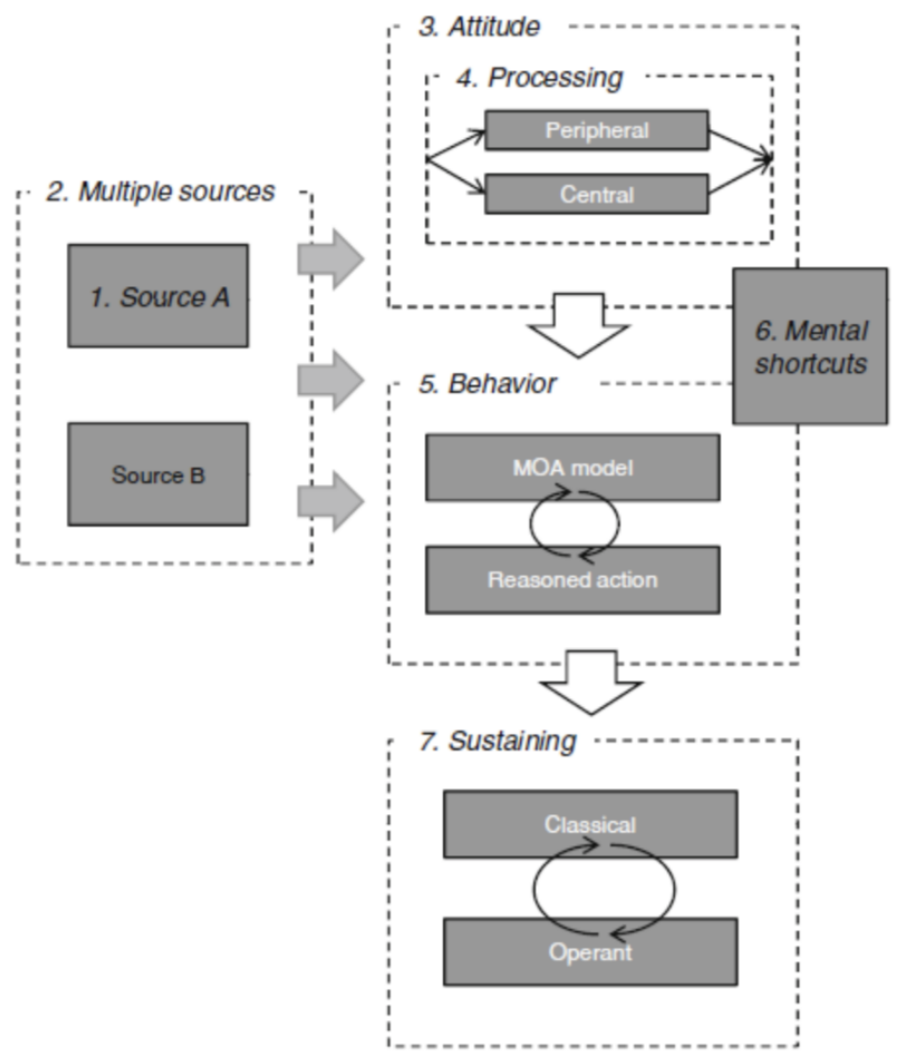

\section{States, transitions, and determinants}

The procedural nature of the model is explicit. The initial state of the process is represented by forming the attitude. The delivering of a persuasive message, combined with the mental shortcuts created at the precedent state, bring the user to perform the behaviour (second state). Ultimately the sustaining can be operated employing the determinant of classical reinforcement or operant conditioning.

Figure 17. Proposed automaton

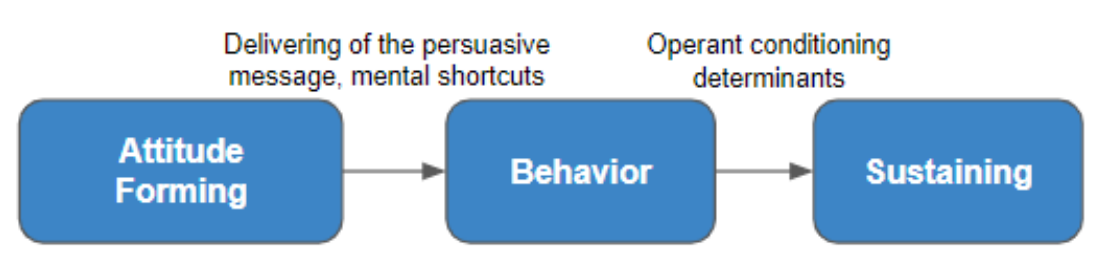

\subsection{The hook model}

Eyal (Eyal 2014) produced a set of guidelines to enhance technological products with habit forming. A general process brings the product from a stage in which it is called "vitamin" (there is no real need for it in the beginning) to a final stage in which the product is called "painkiller" (not using it causes pain). Social media such as Facebook, Instagram or time killer games for smartphone are examples relevant for this process (initially they are used occasionally, then in some cases they become addictive). Eyal theorizes a model made of four stages, the Hook model, in which there is a discrete process of change in the interaction with the user through the following stages: the trigger stage, the action, the reward, and the investment stage. 
The trigger stage recalls the ideas of Fogg as an event that enacts the user (Fogg 2009). Two different types of triggers can be prompted to the user: the external ones (the system tells the user what to do) and the internal ones (the user knows what to do). Internal triggers are often produced by negative emotions. For example, to overcome a sense of loneliness, individuals may use products such as social networks to get in touch with other people.

The action stage follows the principles of the Fogg Behaviour Model (Fogg 2009): to produce the behaviour, a combination of sufficient motivation and ability, and the presence of a prompt are necessary.

Figure 18. The four stages of the Hook Model

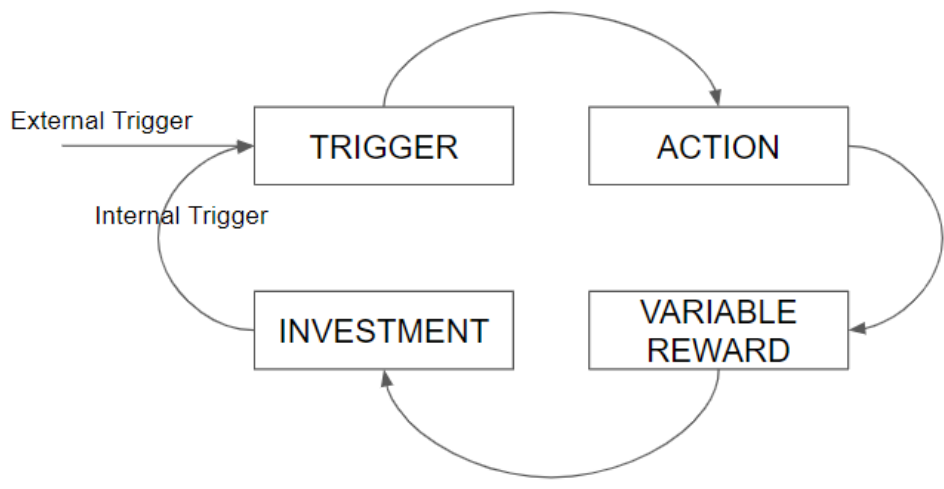

The reward phase is used to acknowledge the behaviour performed in the action stage. Eyal identifies three types of rewards: (1) the reward of the hunt (materialized in resources and goods as money, food, etc.), (2) the reward of the tribe (provided by another user through social-likes, comments, ratings, reviews) and (3) the reward of the self (represented by personal gratification for being consistent with one's own ideas, mastering an ability or for completing a particular task).

The last phase is the investment, where specified users perform a small action that will generate an internal trigger in the future to restart the process. For example, after reviewing a restaurant with a food-application (investment), the system may ask to review other restaurants (trigger) in order to stay in the loop of the application usage.

\section{States, transitions, and determinants}

The Hook model is explicitly based on four main stages, but from a behavioural point of view we can reduce it to three main ones. In the first state, the individual answers to a trigger (external or internal). In the second state, the individual performs the behaviour according to the mechanism described by B.J. Fogg (sufficient motivation and ability plus the presence of a trigger). Thanks to a reward that acts as determinant, the individual travels the last state where a new trigger is generated, permitting the reiteration of the process. 


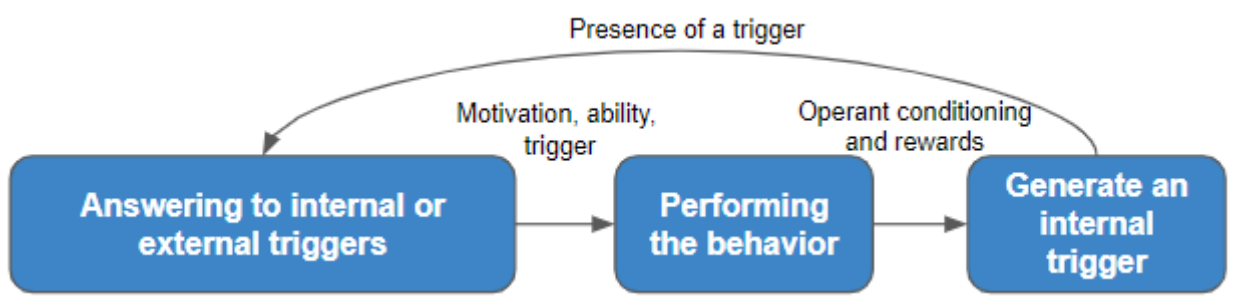

\subsection{The Habit Alteration Model}

The Habit Alteration Model (HAM) theorized by Charlie Pinder et al. (Pinder et al. 2018) synthesises the Dual Process Theory, modern habit theory, and Goal Setting Theory in a common model. The aim is to simplify these theories highlighting how the internal and external factors generate both habitual and non-habitual behaviours.

The model considers the two types of processes from the Dual Process Theory: type 1 processes are fast, automatic, nonconscious, associative; and type 2 processes are slower, deliberative, conscious. Four components contribute to generate behaviours: (1) type1 processes, which are the ones that relate cues to behavioural impulses, (2) type2 processes generated by explicit intentions, (3) the cues of context, and (4) the individual differences (e.g. the impulsivity). The model is based on three phases: filter, prepare, and act as pictured in Figure 20. The dashed lines represent the processes that may run whilst the solid ones represent the continuously running processes.

In the first phase (filter), the processes of type1 and type2 generate a set of cues that are the inputs for the second phase (prepare). For this phase "altering the context" (changing cue properties to affect the priority in the stack) and "priming" (enriching the context to enhance the perception of pushed messages to achieve the behaviour) are considered as effective strategies to pass to the second phase of the model.

In the prepare phase, type1 processes are memorized in the implicit memory and generate a stack of impulses; type 2 processes are memorized in the explicit memory and generate a stack of intentions. Creating new alternatives to default actions, implementing ifthen construct in context, suggesting behavioural directions (ex. notifications) and training the ability of the individual are examples of strategies that may bring to the third phase of the model.

Impulse and intentions compete each other. The ones crossing an act threshold will be delivered to the act phase.

During the last phase (act), the impulses and intentions generate a response and an outcome which constitute new inputs of type 1 and type 2 processes for the first phase. The response may be followed by a self-tracking practice while the outcomes lead to an implicit or explicit feedback to the user. Examples of strategies related to this phase are "selfmonitoring" (providing the subjects of a self-image of their actual behaviour) and "reevaluing the outcome" (implementing/applying operant conditioning techniques). 


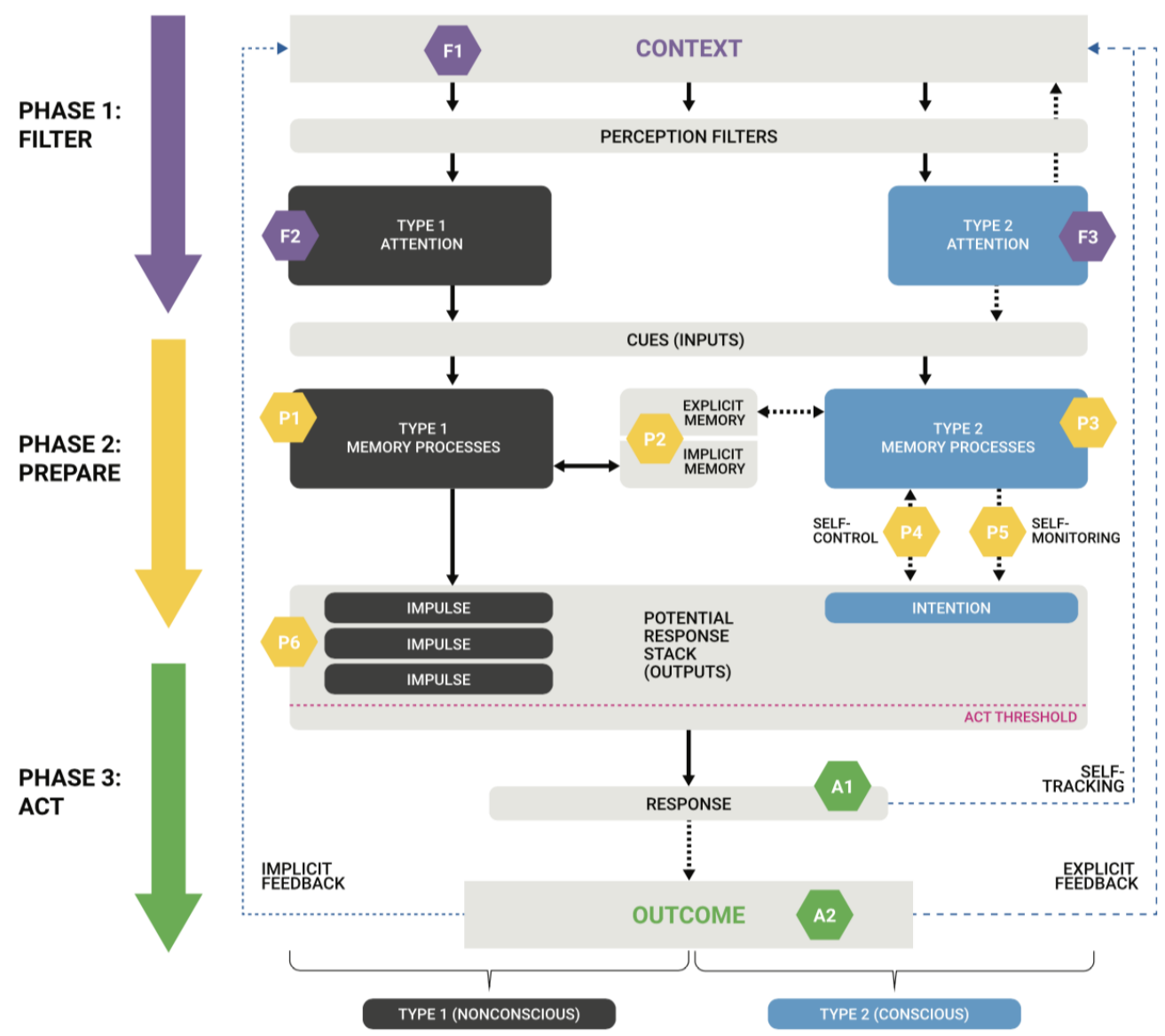

The repetitions of the three phases in stable context becomes more automatic, and may bring people to pass from type 2 processes (slow and conscious) to type1 ones (faster and associative).

\section{States, transitions, and determinants}

HAM may be pictured using states, transitions and determinants even if these concepts are not explicitly defined in the model. However, this formulation has a cognitive/psychological connotation since the model is meant to explain and combine such types of theories. In a first state, the individual filters the context input. From this state, the attention raised by type 1 and type 2 processes brings to a second state where a stack of responses is created. At this state, the impulses and intentions crossing the action threshold permit to perform the behaviour, thereby reaching the third state. Finally the analysis of the responses and of the outcomes permit to have new information to filter the context, and thus to reiterate the process.

Figure 21. Proposed automaton

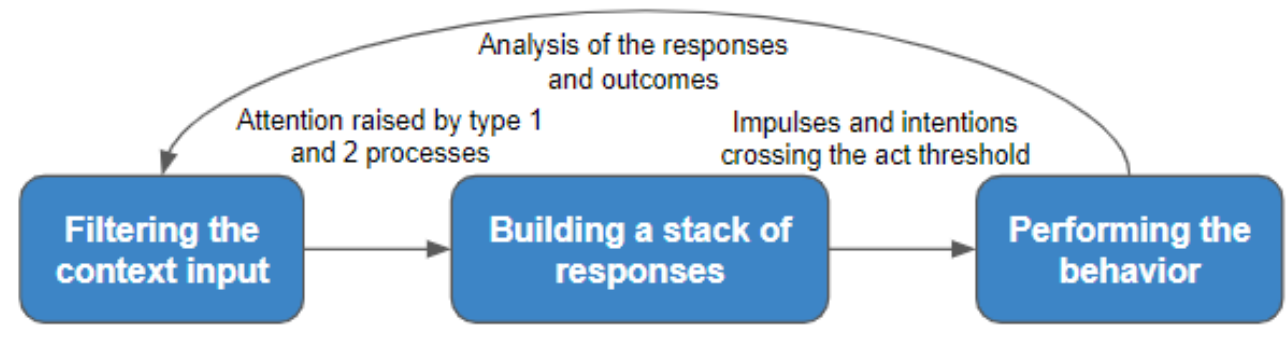




\section{Implementing PERSUASION}

In the previous section, we have reviewed the state-of-the-art focusing on the elements that can be used to describe a process of change through the concepts of states, transitions, and determinants. This paradigm is a first draft toward a new approach to operationalize the persuasive models. In this section, we review a set of core elements supporting this operationalization, which can figure as possible requirements when designing or developing persuasive interactive systems.

\subsection{Context is key}

In the previous section, we have discussed how contextual information is determinant to operate the transition among the states of a process of change. We have also given a first formulation of the context proposed by A.K. Dey (Dey 2001). In the literature, several frameworks have been proposed to account context. Oinas-Kukkonen and Harjumaa (Oinass et al. 2008) (Oinass et al. 2018) for example operate a definition of context aiming at the implementation of interactive systems in the Persuasive System Design model, basing on the analysis of the events, intents and persuasive strategies. Coutaz et al. (Coutaz et al. 2005) describe the context definition for interactive systems on three layers of abstraction: a lower "sensing layer" (e.g. sensors), a "perception layer" (providing symbolic interpretations) in the middle and a higher one "situation and context identification layer" for moving between situations and contexts.

In order to give a concrete example on how the context can be integrated into the development of a persuasive system, we give an example by using the ProSPer framework (Fenicio et al. 2016a). This framework structures the changes to be achieved, and demands to associate the persuasive features to reach these changes by taking advantage of the context detection.

The framework is built up on the MOST model made of four layers: Mission, Objective, Strategy, Tactic (Cadle et al. 2014). The original MOST model has been reorganized into the ProSPer framework to fit the persuasive needs. ProSPer reorganizes the four MOST components into three principal layers: (1) the Problem Layer (where the behaviour is described independently by the application domain), (2) Solution Layer (where the objectives are set and the strategies identified) and (3) the Persuasion Layer (where the strategies, when tailored to the user profile, become tactics and implementable actions) (Fenicio et al. 2016b). 


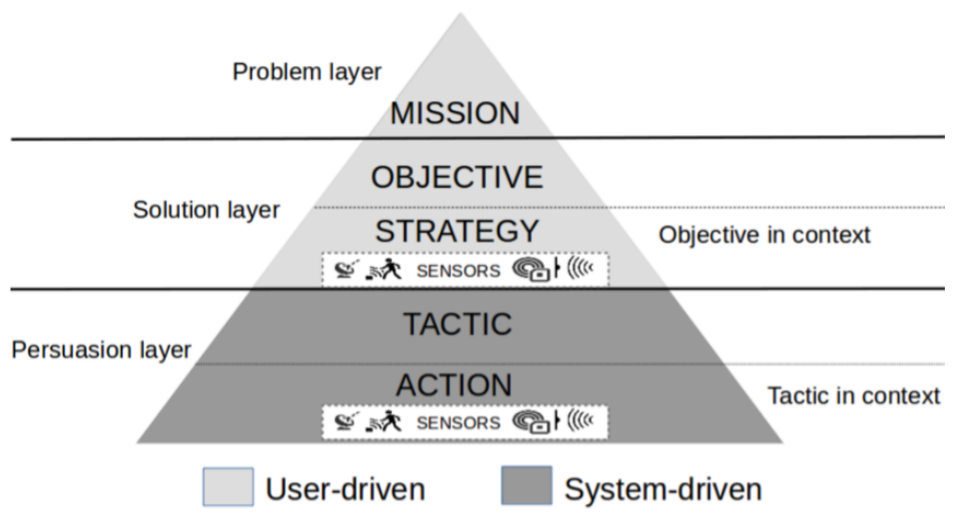

Figure 22 gives a global picture of the ProSPer framework, expliciting the reorganization of the initial layers MOST model for the persuasive needs. In the picture, the two white rectangles with the label "sensors" represent that at the strategy and action levels the context is first sensed (in the strategy layer) and then applied (in the action layer).

We provide a practical example to the reader to understand the functioning of the framework. Let's take the case in which an individual wants to change behaviour in order "to be more rested during the day" (Mission). A generic objective to reach the mission could be to "sleep more". Different strategies could be adopted: going to sleep earlier, wake up later, avoid drinking caffeine, etc. At the strategy level, the context detection is performed: for example, the accelerometer and the GPS sensor of the user's smartphone can give clues on when the user went to sleep and wake up in the last 24 hours. From this information, a set of tactics is set to be driven to the user. These tactics translate into action by applying the detected contextual information, building for example a notification to go to sleep earlier for the next day. The operationalization of the model consists in associating the sensing information to the adequate technology means of the interactive system, and in implementing dedicated persuasive features to put in action the computed strategies in context.

\subsection{Plasticity and adaptation}

A persuasive interactive system has to be capable of supporting the different stages of the process of change. In order to do that, from a Human Computer Interaction point of view, it may be necessary to adapt the user interface in accordance with the process phases.

We propose an example of such adaptation, using the work of Consolvo's UbiFit (Consolvo et al. 2008), and a persuasive system designed for mobile phones, that encourages individuals to perform different types of physical activities and workout. The application alters the smartphone background inserting flowers and butterflies related to different activities performed by the user. In Figure 23, authors propose some screenshots of the application functioning. Part (a) shows the background at the beginning of the week: small butterflies indicate recent goals attainment and the absence of flowers means no activity during the current week. In part (b), the background is changed, showing a garden with flowers. The different flowers represent the different activities performed, explained in part (c) of the image. Large butterfly indicates that the current week goal was met by the user. 
a)

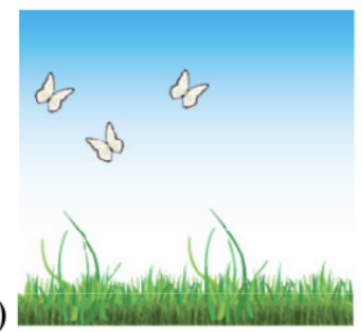

b)

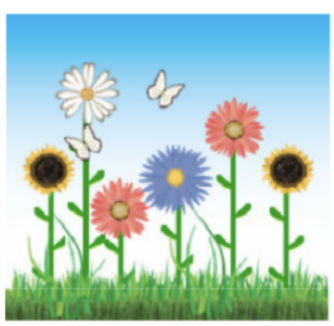

c)

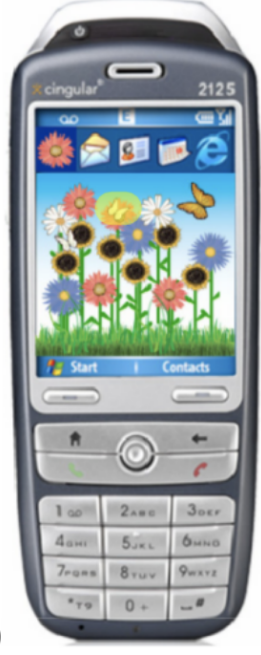

Similarly to Consolvo's work, Nakajima proposes different metaphors to display the behaviour of the user, employing techniques of image morphing to represent the progression or the regression in respect to the objective (Nakajima et al. 2011)(Nakajima et al. 2008). In the article "Characterizing User Roles in $\mathrm{HCl}$ Technologies for Nature Exploration" (Fenicio et al. 2017), we have investigated how to adapt interaction by suggesting different functionalities of the system to the users, according to their own process of change. In particular we have characterized four interactive roles and among which the user can switch in order to maintain active the engagement towards the change.

\subsection{Driving the persuasive features}

Oinas Kukkonen presented a set of guidelines to be used during the design of a persuasive system, formalising the Persuasive System Design approach (PSD) (Oinass et al. 2008), which is based on three designing moments. In a first time designers need to focus on the key issues of the persuasive systems, and in order to facilitate this step he proposes seven postulates to be addressed by designers. The second moment characterizes the analysis of the context: what is the intent of the system? What is the considered persuasive event? What is the strategy to be employed? In a third moment the designers are recommended to focus on the final qualities of the system, concretely evidencing the final persuasive features and how they should be driven to the user. Four categories are considered: primary task support (carrying out of the user's primary task), dialogue support (implementing computer-human dialogue support), system credibility (design a system so that it is more credible) and social support (design the system so that it motivates users by leveraging social influence). The diagram in Figure 24 summarizes the three moments of design proposed by Kukkonen in his PSD model. 

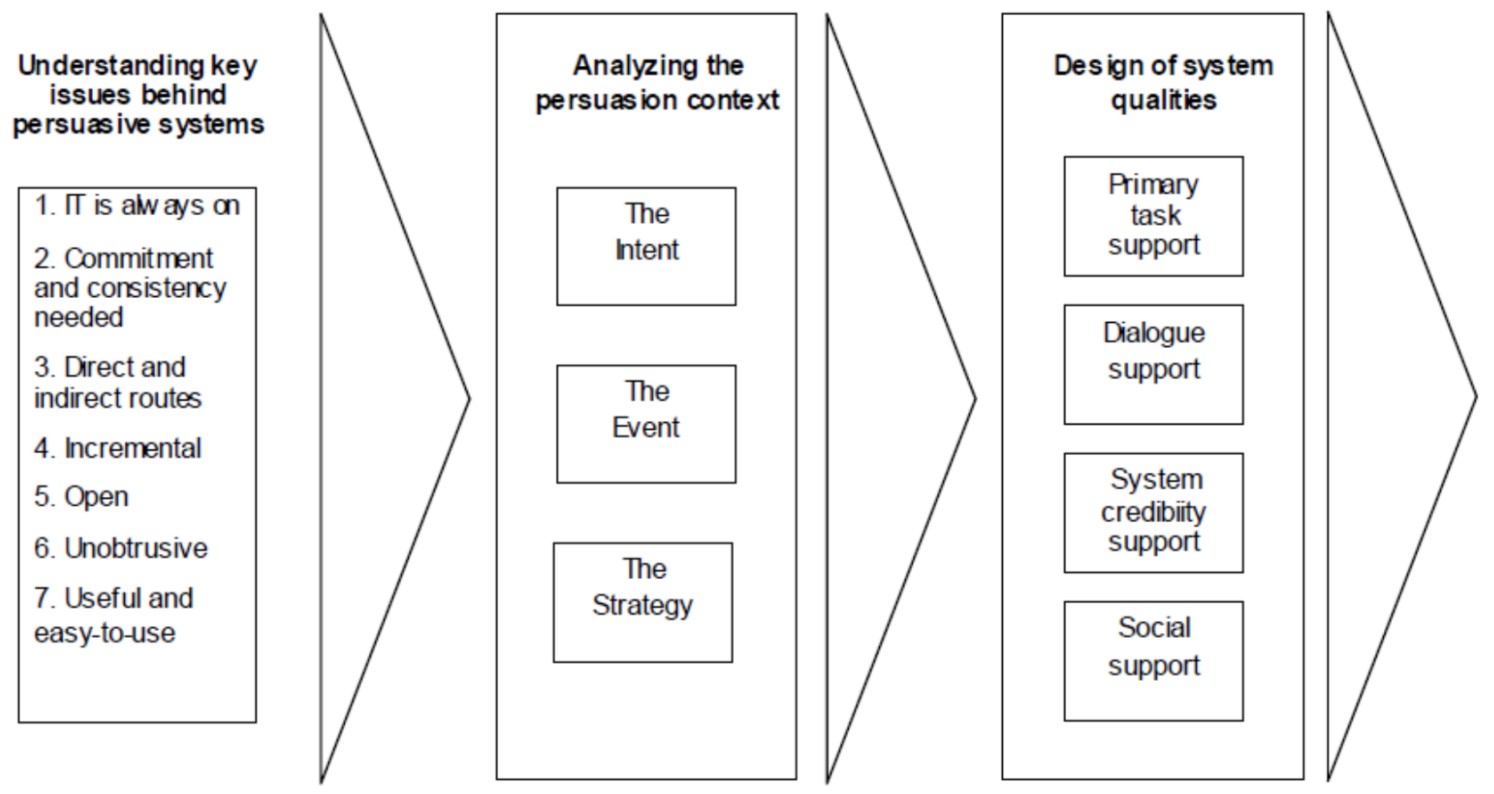

Behavior and/or attitude change

\section{Compared analysis using the “states, transitions, DETERMINANTS" PARADIGM}

In the precedent sections of this work, we have reported on the characterization of the process of change by using two approaches: the first, described different models of the state-of-the-art in persuasion and social psychology through the paradigm of states, transitions and determinants, the second approach evidencing what are the core factors that should not be neglected while approaching the concrete design and development of persuasive systems.

In this section we operate a synthesis of our work performing a comparative analysis of the models discussed in the work. The objective of this analysis is to facilitate the reader in finding differences and analogies between the approaches when considering a model to be operationalized in their persuasive system.

For each model/approach, the analysis reports a set of states, transitions and determinants in order to describe the temporality of the change and its evolution. For certain models such as the Transtheoretical Model of Behaviour change, the sequential evolution is explicit. On the contrary, for some theories, it is not possible to precisely highlight all the components of states, transitions and determinants. For example, in Cialdini's theory of influence, there is no explicit mention to any form of states or transitions. Nevertheless, these theories may describe contextual factors that trigger transitions toward the desired behaviour. For this reason, instead of excluding these theories, we have chosen to consider at least the information on the determinants that may cause transitions between states. 
Table 1. Proposed mapping of models and theories using the "State, Determinants, Transition" (STD) paradigm

\begin{tabular}{|c|c|c|}
\hline $\begin{array}{l}\text { Model/Theory } \\
\text { [main authors] }\end{array}$ & $\begin{array}{l}\text { Proposed } \\
\text { [STD] }\end{array}$ & Proposed mapping \\
\hline $\begin{array}{r}\text { Operant } \\
\text { conditioning } \\
{[\text { Skinner] }} \\
\text { (McLeod 2009) }\end{array}$ & TD & $\begin{array}{l}\text { Transitions: represented by the three-term-contingency. } \\
\text { Determinants: environmental conditions or stimulus changes. }\end{array}$ \\
\hline $\begin{array}{r}\text { Influence } \\
\text { [Cialdini] } \\
\text { (Cialdini 1987) }\end{array}$ & $\mathrm{D}$ & Determinants: Reciprocity, Scarcity, Authority, Consistency, Liking, Consensus. \\
\hline $\begin{array}{r}\text { Elaboration } \\
\text { Likelihood model } \\
\text { [Cacioppo] } \\
\text { (Petty et al. 1986) }\end{array}$ & STD & $\begin{array}{l}\text { States: delivering of message, elaboration of message, impression on individual, } \\
\text { attitude change. } \\
\text { Transitions: central and peripheral route transitions. } \\
\text { Determinants: ability, motivation, (positive and negative) shift, (positive and } \\
\text { negative) impression. }\end{array}$ \\
\hline $\begin{array}{l}\text { Social cognitive } \\
\text { theory } \\
\text { [Bandura] } \\
\text { (Bandura 2001) }\end{array}$ & $\mathrm{D}$ & $\begin{array}{l}\text { Determinants: expected behavioural outcomes, environment and personal factors } \\
\text { including self-efficacy. Three kinds of factors cognitive, environmental and behavioural } \\
\text { impact the determinant of behaviour. }\end{array}$ \\
\hline $\begin{array}{l}\text { Theory of } \\
\text { planned behaviour } \\
\text { [Ajzen] (Ajzen } \\
\text { 1991) }\end{array}$ & STD & $\begin{array}{l}\text { States: evaluating stage, intention forming, behaviour performing. } \\
\text { Transitions: multiple loops may be necessary to form the intention. } \\
\text { Determinant: intention, perceived behavioural control and situational conditions. }\end{array}$ \\
\hline $\begin{array}{l}\text { Fogg Behaviour } \\
\text { model } \\
\text { [Fogg] (Fogg } \\
\text { 2009) }\end{array}$ & STD & $\begin{array}{l}\text { States: not performing the behaviour, performing intermediate behaviours, } \\
\text { performing the final behaviour. } \\
\text { Transition: aiming at increasing the levels of motivation and ability. } \\
\text { Determinant: core motivations (for motivation), simplicity factors (for ability) and } \\
\text { prompt (for action). }\end{array}$ \\
\hline $\begin{array}{l}\text { Motivation } \\
\text { Opportunity Ability } \\
\text { [Michie] (Michie } \\
\text { et al. 2011) }\end{array}$ & STD & $\begin{array}{l}\text { States: forming the intention, performing the behaviour. } \\
\text { Transitions: consecutive among the states, with a loop to iterate the process. } \\
\text { Determinants: social norm, attitude, opportunity, ability. New abilities determine the } \\
\text { loop transition. }\end{array}$ \\
\hline $\begin{array}{l}\text { The } \\
\text { Transtheoretical Model } \\
\text { [Prochaska] } \\
\text { (DiClemente et al. } \\
\text { 1998) }\end{array}$ & STD & $\begin{array}{l}\text { States: pre-contemplation, contemplation, preparation, action, and maintenance. } \\
\text { Transitions: consecutive among the states, undefined iteration for each state, and } \\
\text { possibility of relapse to a precedent state. } \\
\text { Determinants: the ten processes of change combined with the self-efficacy and } \\
\text { decisional balance. }\end{array}$ \\
\hline $\begin{array}{c}\text { Ambient } \\
\text { Persuasion Model } \\
\text { [Kaptein] } \\
\text { (Kaptein et al. 2010) }\end{array}$ & STD & $\begin{array}{l}\text { States: attitude forming, behaviour change, sustaining the change. } \\
\text { Transition: gradually represents the process from the attitude forming to the } \\
\text { maintenance. } \\
\text { Determinants: delivering of persuasive message, mental shortcuts, and operant } \\
\text { conditioning. }\end{array}$ \\
\hline $\begin{array}{l}\text { The hook model } \\
\text { [Eyal] (Eyal } \\
\text { 2014) }\end{array}$ & STD & $\begin{array}{l}\text { States: answering to an internal/external trigger, performing behaviour, generate a } \\
\text { new trigger } \\
\text { Transitions: consecutive transitions based on an iterative process. } \\
\text { Determinants: cognitive theory determinants, Fogg's behaviour model } \\
\text { determinants, operant conditioning determinants. }\end{array}$ \\
\hline
\end{tabular}




\begin{tabular}{|c|c|c|}
\hline $\begin{array}{c}\text { The Habit } \\
\begin{array}{c}\text { Alteration Model } \\
\text { [Pinder] (Pinder } \\
\text { et al. 2018) }\end{array}\end{array} \quad$ STD & $\begin{array}{c}\text { States: the filtering the context input, building a stack of responses, performing the } \\
\text { behaviour. } \\
\text { Transitions: consecutive and depending on the Type1 or Type2 process. Iterative } \\
\text { transitions are present to restart the process. } \\
\text { Determinants: Type1 and Type2 attention, implicit and explicit memory, impulses } \\
\text { and intentions. Iteration done with self-tracking and explicit feedback. }\end{array}$ \\
\hline
\end{tabular}

In table 1, we have operated a synthesis of the models and approaches reviewed in this work evidencing the concepts of state, transitions and determinant. The column SDT summarizes where an analysis using the three components $S$ (State), T (Transition) and (D) Determinant can be partially or completely operated. The next column proposes a mapping of the three components showing an example of how the set of states, transitions and determinants may be defined.

\section{Discussion ANd LIMITATIONS}

The synthesis operated in this work leads to different considerations in the application of the "state, determinant, transitions" paradigm.

\subsection{Discussion}

A first consideration is related to the presence of iterative transitions in the processes. Several theories involve a transition that refines, through repetition, the achieved result: tiny steps approach in Fogg's behavioural model (Fogg 2009), feedback and self-tracking in the HAM model (Pinder et al. 2018), investment in the Hook model (Eyal 2014). We notice that the iterative process is often triggered using the determinants of the operant conditioning, where the expectation of a new reward brings the subject to commit to another cycle of the process. The MOA model (Maclnnis et al. 1991) instead triggers the iteration by the discovery of new abilities that generate new motivations to the users.

From an operational point of view, this consideration suggests the possibility to link different classes of persuasive features to specific types of transitions in the process of change. For instance, the iterative loops in a process may be linked to the persuasive features of the Dialogue Support category of the PSD model (Oinass et al. 2008) where the technique of reward is implemented. Other links may be operated. For example, initial transitions in the process may be linked to persuasive features oriented to increase the confidence in the system, through features implementing trustworthiness, authority and verifiability, as described in the credibility support category of the PSD model (Oinass et al. 2008).

A second consideration is about the evolving nature of the process. We have depicted the process through states and transitions caused by determinants. These three components are not static. They may evolve during the process of change. For example, several theories mention the creation of an intention (MOA model Likelihood model, Theory of planned behaviour) or of an impulse (HAM model). These new factors become new determinants for the successive transitions in the process. In addition, for several models, it is not possible to predict the set of states that will be travelled across during the process of change. The path for change needs to be estimated dynamically during the process.

\subsection{Limitations}


We have reviewed the state-of-the-art in persuasion by applying the paradigm of states, transitions and determinants defined in the first section. Successively we have reviewed some key issues that need to be addressed when approaching the design and the development of persuasive interactive systems. Finally, we have summarised the proposed mapping of each work into a comparative table to be used as support for designers of persuasive systems.

The mapping operated in this article has considered a set of works from the state-ofthe-art in persuasion, social theories, and psychology. However, this set can be extended with additional models to answer some specific design and implementation needs. In addition, the proposed mappings are not intended to be unique: other possible formulations can be operated provided that they respect our definition of states, transitions, and determinants.

We noticed that it is not always possible to find a complete mapping to the three concepts of states, transitions and determinants. This mostly applies to social cognitive theories, to behaviourist theories and to the influence principles where in most of the cases it is possible to characterize just the determinant that may persuade the individual to progress along the change, rather than a precise set of states to be travelled.

\section{References}

- Fogg, Brian J. "A behaviour model for persuasive design." Proceedings of the 4th international Conference on Persuasive Technology. ACM, 2009.

- Pinder, C., Vermeulen, J., Cowan, B. R., \& Beale, R. (2018). Digital behaviour change interventions to break and form habits. ACM Transactions on Computer-Human Interaction (TOCHI), 25(3), $15 .$.

- Oinas-Kukkonen, H. (2010, June). Behavior change support systems: A research model and agenda. In International Conference on persuasive technology (pp. 4-14). Springer, Berlin, Heidelberg.West, Robert, and Jamie Brown. Theory of addiction. John Wiley \& Sons, 2013.

- McLeod, S. A. (2007). Bf skinner: Operant conditioning. Retrieved September, 9, 2009.Staddon, John ER, and Daniel T. Cerutti. "Operant conditioning." Annual review of psychology 54.1 (2003): 115-144.

- Bijou, S. W. (1957). Patterns of reinforcement and resistance to extinction in young children. Child Development, 47-54.Eyal, Nir. Hooked: How to build habit-forming products. Penguin, 2014.

- Fogg, B. J. (1998, January). Persuasive computers: perspectives and research directions. In Proceedings of the SIGCHI conference on Human factors in computing systems (pp. 225232). ACM Press/Addison-Wesley Publishing Co..Cialdini, Robert B. Influence. Vol. 3. Port Harcourt: A. Michel, 1987.

- Milgram, S., \& van Gasteren, L. (1974). Das Milgram-Experiment. ) Rowohlt.James, William. The principles of psychology. Read Books Ltd, 2013.

- Petty, R. E., \& Cacioppo, J. T. (1986). The elaboration likelihood model of persuasion. In Communication and persuasion (pp. 1-24). Springer, New York, NY.Dey, Anind K. "Understanding and using context." Personal and ubiquitous computing 5.1 (2001): 4-7.

- Bandura, A. (2001). Social cognitive theory: An agentic perspective. Annual review of psychology, 52(1), 1-26.

- Fenicio, A., \& Calvary, G. (2015, November). Persuasion Through an Ambient Device: Proof of Concept and Early Evaluation of CRegrette, a Smoking Cessation System. In European Conference on Ambient Intelligence (pp. 252-267). Springer, Cham. 
- Hamari, J., Koivisto, J., \& Pakkanen, T. (2014, May). Do persuasive technologies persuade?-a review of empirical studies. In International conference on persuasive technology (pp. 118136). Springer, Cham.

- Hughes, J. (2007, January). The ability-motivation-opportunity framework for behavior research in IS. In 2007 40th Annual Hawaii International Conference on System Sciences (HICSS'07) (pp. 250a-250a). IEEE.

- Maclnnis, D. J., Moorman, C., \& Jaworski, B. J. (1991). Enhancing and measuring consumers' motivation, opportunity, and ability to process brand information from ads. Journal of marketing, 55(4), 32-53.

- Michie, S., Van Stralen, M. M., \& West, R. (2011). The behaviour change wheel: a new method for characterising and designing behaviour change interventions. Implementation science, 6(1), 42.

- DiClemente, C. C., \& Prochaska, J. O. (1998). Toward a comprehensive, transtheoretical model of change: Stages of change and addictive behaviors.

- He, H. A., Greenberg, S., \& Huang, E. M. (2010, April). One size does not fit all: applying the transtheoretical model to energy feedback technology design. In Proceedings of the SIGCHI conference on human factors in computing systems (pp. 927-936). ACM.

- Kaptein, M. C., Markopoulos, P., De Ruyter, B., \& Aarts, E. (2010). Persuasion in ambient intelligence. Journal of Ambient Intelligence and Humanized Computing, 1(1), 43-56.

- Fenicio, A., Calvary, G., Laurillau, Y., \& Vanderdonckt, J. (2016, July). ProSPer: a MOST model extension applied to persuasive interactive systems. In Proceedings of the 30th International BCS Human Computer Interaction Conference: Companion Volume (p. 39). BCS Learning \& Development Ltd..

- Fenicio, A., Calvary, G., Laurillau, Y., \& Vanderdonckt, J. (2016, October). ProSPer: modeling the change, driving the persuasion. In Actes de la 28ième conférence francophone sur I'Interaction Homme-Machine (pp. 59-69). ACM.

- Consolvo, S., McDonald, D. W., Toscos, T., Chen, M. Y., Froehlich, J., Harrison, B., ... \& Smith, I. (2008, April). Activity sensing in the wild: a field trial of ubifit garden. In Proceedings of the SIGCHI conference on human factors in computing systems (pp. 1797-1806). ACM.

- Nakajima, T., \& Lehdonvirta, V. (2013). Designing motivation using persuasive ambient mirrors. Personal and ubiquitous computing, 17(1), 107-126.

- Nakajima, T., Kimura, H., Yamabe, T., Lehdonvirta, V., Takayama, C., Shiraishi, M., \& Washio, Y. (2008, October). Using aesthetic and empathetic expressions to motivate desirable lifestyle. In European Conference on Smart Sensing and Context (pp. 220-234). Springer, Berlin, Heidelberg.

- Fenicio, A., Calvary, G., Laurillau, Y. (2017)- Characterizing User Roles in HCl Technologies for Nature Exploration In The 2nd workshop on NatureCHI - Unobtrusive User Experiences with Technology in Nature (MobileHCl '17).

- Oinas-Kukkonen, H., \& Harjumaa, M. (2008, June). A systematic framework for designing and evaluating persuasive systems. In International conference on persuasive technology (pp. 164-176). Springer, Berlin, Heidelberg.

- Oinas-Kukkonen, H., \& Harjumaa, M. (2009). Persuasive systems design: Key issues, process model, and system features. Communications of the Association for Information Systems, 24(1), 28.

- Fenicio, A., Laurillau, Y., \& Calvary, G. (2017, November). Persuasive Events and User's Roles in Mobile-Based Interactive Solutions for Nature Discovery. In Proceedings of the 14th EAl International Conference on Mobile and Ubiquitous Systems: Computing, Networking and Services (pp. 511-519). ACM.

- ThØgersen, J. (1995). Understanding of consumer behaviour as a prerequisite for environmental protection. Journal of consumer policy, 18(4), 345-385.

- Ajzen, I. (1991). The theory of planned behavior. Organizational behavior and human decision processes, 50(2), 179-211. 
- Coutaz, J., \& Crowley, J. L. (2005). CONTEXT is KEY. Communications of the ACM, 48(3), 49.

- Cadle, J., Paul, D., \& Turner, P. (2014). Business analysis techniques. Chartered Institute for IT.

- Kaptein, M. C. (2012). Personalized persuasion in ambient intelligence.

\section{BIOgRAPHIE}
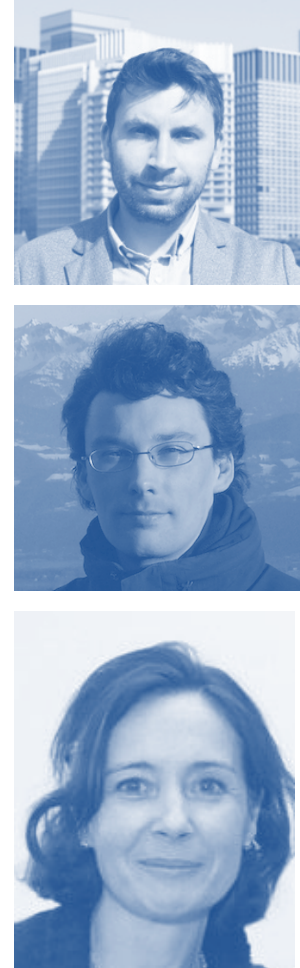

\section{Alessandro FENICIO}

is a 3rd year Ph.D. student at the University Grenoble Alpes. His investigation concerns persuasive technologies and human computer interaction. Alessandro has presented his works in several international conferences, workshops and seminaries, producing different publications. His background in software engineering permitted him to effectively apply his investigation to the research and development departments of private enterprises.

\section{Yann LAURILLAU}

est Maître de Conférences HDR en Informatique à l'Université Grenoble Alpes. Ses travaux portent sur l'interaction homme-machine symbiotique appliquée plus spécifiquement aux systèmes multi-utilisateurs, multi-surfaces, incluant l'interaction gestuelle tangible. Son approche porte sur les outils de conception de tels systèmes, autant sur le plan conceptuel que technique. Depuis quelques années, ses recherches portent également sur les systèmes persuasifs.

\section{Gaëlle CALVARY}

est professeure en Informatique à Grenoble INP. Ses travaux portent sur la plasticité des Interfaces Homme-Machine (IHM). Son but est de fournir des méthodes, modèles et outils pour soutenir le développement d'IHM plastiques. L'approche qu'elle a le plus explorée est l'Ingénierie Dirigée par les Modèles. Elle défend l'unification des phases de conception, d'exécution et d'évaluation autour de modèles et de transformations de modèles. Elle explore aujourd'hui la plasticité comme levier de persuasion technologique. 